\title{
Extension-Type Pulling-and-Running Gear for Investigations of Subglacial Lake Vostok
}

\author{
Nikolai I. Vasilev ${ }^{1}$, Igor P. Timofeev ${ }^{1}$, Alexey V. Bolshunov ${ }^{1 *}$, \\ Sergei A. Ignatiev ${ }^{1}$, Andrei N. Dmitriev ${ }^{1}$ \\ ${ }^{1}$ St. Petersburg Mining University, 21 Line, 2, Vasilyevsky Island, 199106 St. Petersburg, Russia. \\ *Corresponding author: av_bol@mail.ru
}

\begin{abstract}
The paper reviews a key issue concerned with development of technologies and technical means required for investigation of subglacial lakes in Antarctica and Lake Vostok in particular, which would secure environmental safety of the operations. The main objectives of the research activities reviewed in the paper was to justify design concepts of the equipment to be used for penetration into Subglacial Lake Vostok and to develop a pulling-and-running gear required for such penetration. Reviews of research publications and a patent search confirmed that neither the standard designs nor advanced developments of pulling-and-running gears are suitable for the proposed technology of penetration into Subglacial Lake Vostok. A fundamentally new and patent-protected design of the pulling-and-running gear was developed in agreement with the defined specifications. The developed penetration technology into the subglacial lake as well as the pulling-and-running gear design for its implementation not only secure the environmental safety of survey execution, but also meet a number of key requirements. These requirements include stability of the borehole interval filled with the lake water, prevention of the delivery vehicle freezing on to its walls, reliability and trouble-free operation of all arrangements and systems used to deliver the research tools and instruments into the lake.
\end{abstract}

Keyword - Antarctica, Lake Vostok, Pulling-and-Running Gear

\section{INTRODUCTION}

Lake Vostok is the largest subglacial lake in Antarctica [1,2,3] was penetrated for the first time ever on February 5th, 2012, by specialists of the St. Petersburg State Mining University and the Arctic and Antarctic Research Institute [4]. Further research of Lake Vostok envisages sampling of the lake water and bottom sediments, which due to the unique character of the surveyed ecosystem needs to be executed in compliance with the following key requirements:

- Environmentally safe way of work execution;

- Stability of the borehole interval filled with the lake water, and prevention of delivery vehicle freezing on to its walls;

- Reliability and trouble-free operation of all arrangements and systems used to deliver the research tools and instruments into the lake.

A borehole conditioning technology was developed for lake water and bottom sediment sampling using Borehole 5G-3 in order to meet the first two requirements mentioned above. This technology envisages the following six stages (Fig. 1).

The first stage assumes drilling a $138-\mathrm{mm}$ borehole down to the depth of 1 meter to the borehole-Lake Vostok boundary using a regular mechanical drilling assembly $[5,6,7]$ (Fig. 1a).

The second stage consists in reaming the bottom section of the borehole up to $300 \mathrm{~mm}$ in diameter within the depth interval of 10 meters from the borehole bottom (Fig. 1b). It is intended to use a mechanical reamer mounted on a mechanical drilling assembly to perform this operation $[6,8]$.

Borehole drilling during the third stage is done with a thermal drilling assembly that penetrates through the final one-meter-thick ice plug until the borehole reaches the lake with a 300-mm opening (Fig. 1c). The design of the thermal drilling assembly is based on the design concepts that have been successfully implemented in thermal drilling tools used for borehole drilling in glaciers $[9,10,11,12]$.

The forth stage involves a controlled ingress of the lake water into the reamed section of the borehole up to the height of $10 \mathrm{~m}$ above the lake surface (Fig. 1d).

A delivery vehicle [13] is lowered into the reamed section of the borehole during the fifth stage. This delivery vehicle carries a module with research instruments as well as the pulling-and-running gear inside a sealed winch compartment filled with distilled water (Fig. 1e). 
During the final sixth stage, the research module [13] is lowered into the lake using the pulling-and-running gear. The module enters the lake water leaving the distilled water compartment, which secures environmental safety of the operation (Fig. 1f).

Sampling of the lake water and bottom sediments will be done using the research module run down with a line that allows the module to be stopped at predefined depths. The pulling-and-running gear required to move the module within the lake water has to meet the following technical specifications:

- dimensions: up to $2000 \mathrm{~mm}$ in length and up to $110 \mathrm{~mm}$ in diameter;

- coiling length: up to $700 \mathrm{~m}$;

- maximum weight of the research module: up to $20 \mathrm{~kg}$;

- travelling speed of the research module: $0.25 \mathrm{~m} / \mathrm{s}$.
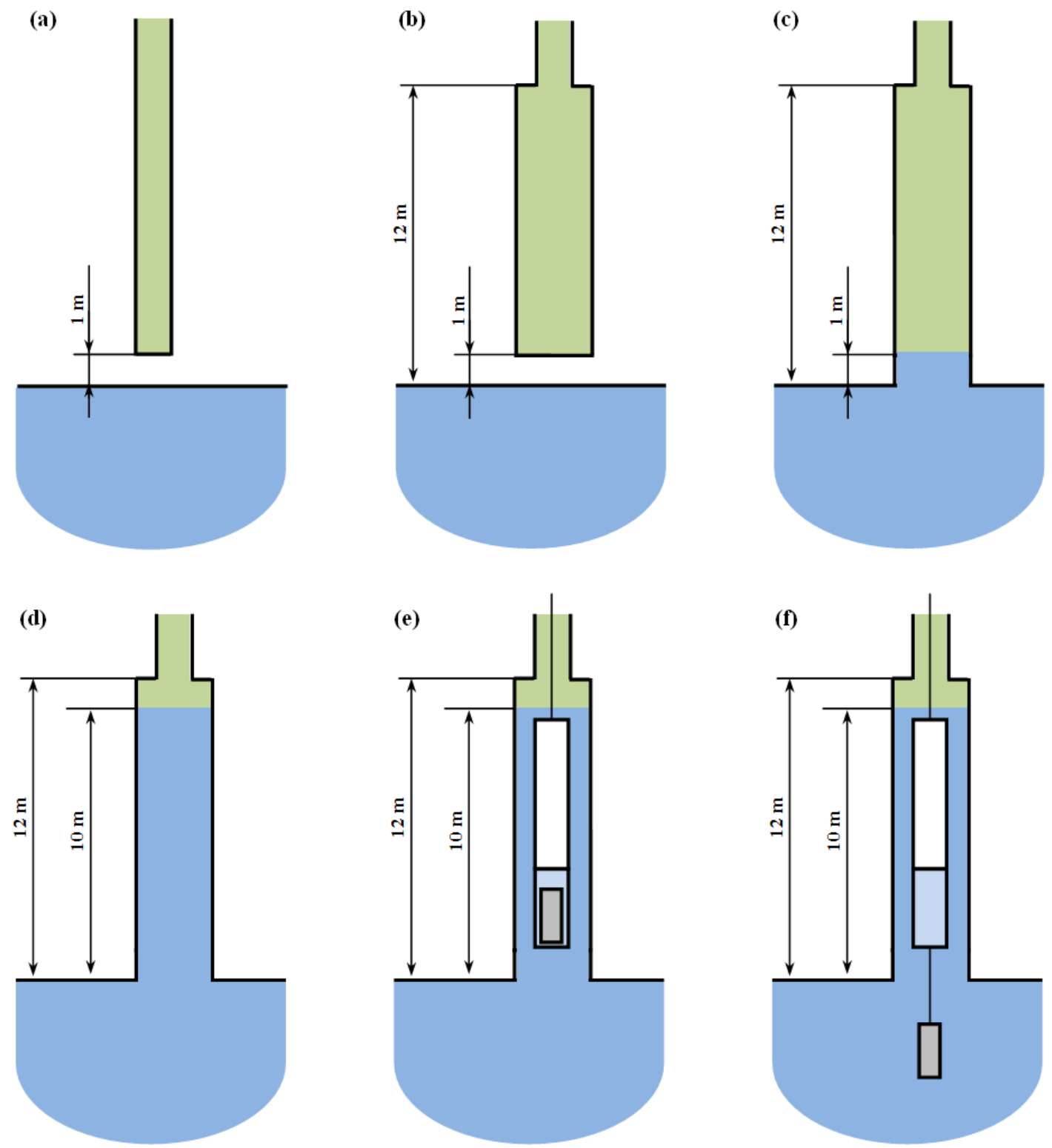

Fig. 1. Technology of borehole conditioning before penetration into Lake Vostok a - borehole drilling with mechanical drilling assembly; $b$ - borehole reaming with mechanical reaming assembly; $\mathrm{c}$ - borehole reaming with thermal reaming assembly; $\mathrm{d}$ - ingress of lake water into reamed section of borehole; e - deployment of delivery vehicle in the reamed section of borehole; $f$ - runnung of research module into lake

The performed analysis of commercially available pulling-and-running gears proved that none of them meets the above requirements, above all in terms of their dimensions. Specific features of further surveys of Subglacial Lake Vostok and the delivery vehicle design based on proven parts of the drilling assembly require development of a fundamentally new design of the pulling-and-running gear. 
A patent search performed to select a design prototype for the pulling-and-running gear did not give any positive results. However, it confirmed that the following design solutions can be used in the arrangement to be developed: a gear with a reeving system, an endless screw gear and an extension-type gear. Each of the designs has its advantages and regrettably its drawbacks.

Thus, if one or another design solution is used as the basis, it will be necessary to adopt it to fit the conditions and technical specifications for the pulling-and-running gear required for water and bottom sediment sampling from Lake Vostok.

This paper considers in details a pulling-and-running gear of the extension-type.

\section{METHODOLOGICAL FRAMEWORK}

Fig. 2 shows a kinematic diagram of the extension-type pulling-and-running gear.

The gear housing (1) accommodates a spooling assembly $(2)$ mounted on bearings $(3,4)$ and fitted with an internal gear rim (5) driven by a driving unit (6) through a tooth wheel (7) and an idler (8). A drive spindle (9) with support $(10,11)$ is located inside the drum and is driven by the driving unit $(6)$. The housing (1) is rigidly connected to a fixed sleeve (12) which houses three spools $(13,14,15)$ of different diameters one inside the other.
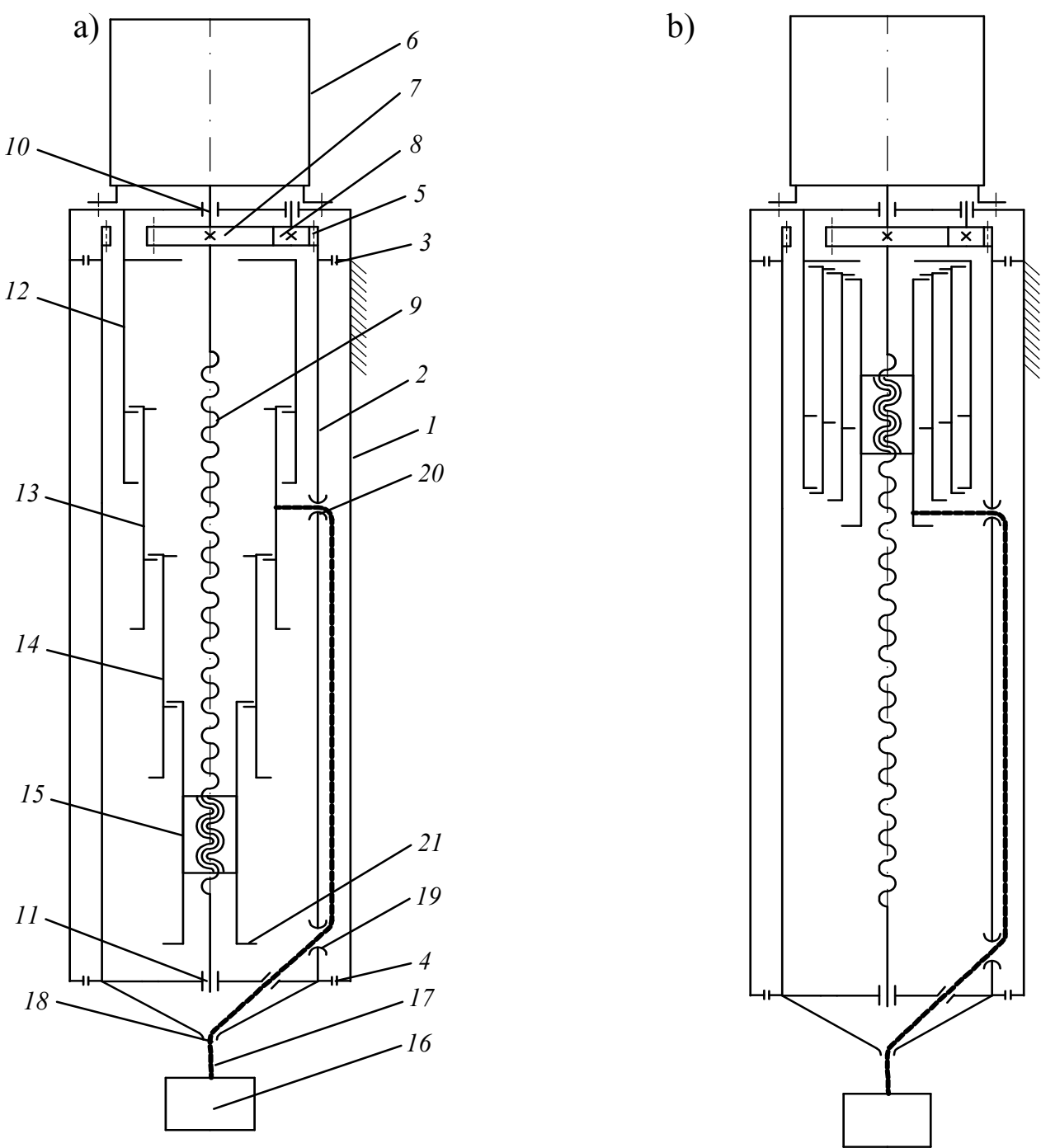

Fig. 2. Kinematic diagram of extension-type pulling-and-running gear: $a$ - running a load; $b$ - pulling a load

The smallest spool (15) has an integral nut which interacts with the drive spindle (9). A load (16) is attached to a carrying line (17) that passes through the central hole $(18)$ and side ports $(19,20)$ of the spooling assembly (2) and is connected to the largest spool (13). In order to secure axial movement of the spools $(13,14,15)$ and prevent their rotation in relation to the drive spindle (9) axis, the assembly is fitted with guide keys (not shown in the drawings). The extension sequence of the spools $(13,14,15)$ is secured by a number of spring balls (not 
shown in the drawings). The end face of the smallest spool (15) is fitted with a safety washer (21) that prevents carrying line dislocation during the winding and rewinding operations.

In the initial position shown in Fig. 2a, all the spools $(13,14,15)$ are in the extended position relative to each other and the fixed sleeve (12). At this stage, the working length of the carrying line (17) is completely reeled on the external faces of the spools $(13,14,15)$ and the load $(16)$ is in the upper position.

Running of the load is done in the following way. When the driving unit (6) is actuated, the drive spindle (9) receives the rotational force and drives the smallest spool (15), which starts progressively moving upwards along the drive spindle (9) axis. Rotation of the drive spindle (9) is transferred to the tooth wheel (7) and is delivered to the internal gear rim (5) of the spooling assembly (2) via the idler (8) fixed on the housing (1). The spooling assembly (2) rotates together with the carrying line (15) that passes through the openings $(18,19,20)$; the carrying line starts unwinding from the largest spool (13) and the load is running down. While unwinding the carrying line, the largest spool (13) shifts towards the fixed sleeve (12) together with the guide key. Unwinding of the carrying line from the other two spools (14 and 15) is done in the same way. When the carrying line is completely unwound, the load reaches the lowest position, i.e. the required depth.

Load pulling is done by changing the direction of the drive spindle (9) rotation by reversing the driving unit (6) as it is shown in Fig. 2b. This changes the rotation direction of the spooling assembly (2), and the carrying line starts winding up onto the lowest spool (15). The smallest spool (15) will gradually shift together with the guide key away from the middle spool (14) until the guide key stops against the guiding groove of the middle spool (14). The middle spool (14) starts moving downwards and the carrying line (17) winds up onto the surface of this spool (14). The winding process continues and the spools keep on extending.

Based on the accepted kinematic diagram and taking into account the required carrying line capacity and dimensions of the pulling-and-running gear, the number of spools and their diameters can be combined in the following way:

- Number of spools: 3 pcs. - Diameters: dsp $1=70 \mathrm{~mm}$, dsp2 $=60 \mathrm{~mm}$, dsp $3=50 \mathrm{~mm}$;

- Number of spools: 4 pcs. - Diameters: dsp $1=70 \mathrm{~mm}$, dsp2 $=60 \mathrm{~mm}$, dsp3 $=50 \mathrm{~mm}$; dsp $4=40 \mathrm{~mm}$;

- Number of spools: 5 pcs. - Diameters: dsp1 $=70 \mathrm{~mm}, \mathrm{dsp} 2=60 \mathrm{~mm}, \mathrm{dsp} 3=50 \mathrm{~mm}$; dsp $4=40 \mathrm{~mm}$, $\mathrm{dsp} 5=30 \mathrm{~mm}$.

The working length of the extension part will equal

$$
L_{w}=n_{s p} l_{w l \_s p} \quad,
$$

where $n_{s p}$ is the number of spools, pcs.; $l_{w l s p}$ is the working length of the spool, $\mathrm{m}$.

In order to secure uniformity of the carrying line winding onto the spool surface, the number of wraps shall be limited to 4 per $1 \mathrm{~mm}$ of the spool length with the carrying line diameter $d_{l}=1 \mathrm{~mm}$. Then the average winding diameter of the spools will equal: $d_{a v_{-} s p 1}=74 \mathrm{~mm}, d_{a v_{\_} s p 2}=64 \mathrm{~mm}, d_{a v_{-} s p 3}=54 \mathrm{~mm} ; d_{a v \_s p 4}=44 \mathrm{~mm}$, $d_{a v_{-} s p 5}=34 \mathrm{~mm}$.

The carrying line capacity of the extension section will equal

$$
L_{l}=\sum_{i=1}^{n_{s p}} 4 \pi d_{a v \_s p_{i}} \frac{l_{w l \_s p}}{d_{l}}
$$

\begin{tabular}{|c|c|c|c|c|c|c|}
\hline \multirow{3}{*}{$I_{w l \_s p}, \mathbf{m}$} & \multicolumn{6}{|c|}{ Number of spools } \\
\hline & \multicolumn{2}{|c|}{3} & \multicolumn{2}{|c|}{4} & \multicolumn{2}{|c|}{5} \\
\hline & $L_{w l}, \mathbf{m}$ & $L_{l}, \mathrm{~m}$ & $L_{w l}, \mathbf{m}$ & $L_{l}, \mathbf{m}$ & $L_{w l}, \mathbf{m}$ & $L_{l}, \mathbf{m}$ \\
\hline 0.20 & 0.60 & 482.4 & 0.80 & 592.8 & 1.00 & 678.4 \\
\hline 0.22 & 0.66 & 530.7 & 0.88 & 652.1 & 1.10 & 746.3 \\
\hline 0.24 & 0.72 & 578.9 & 0.96 & 711.4 & 1.20 & 814.1 \\
\hline 0.26 & 0.78 & 622.1 & 1.04 & 770.6 & 1.30 & 881.9 \\
\hline 0.28 & 0.84 & 675.3 & 1.12 & 829.9 & 1.40 & 949.7 \\
\hline 0.30 & 0.90 & 723.6 & 1.20 & 889.2 & 1.50 & 1017.6 \\
\hline
\end{tabular}

TABLE I Dependence of carrying line capacity $L_{l}$ on spool working length

Table 1 shows that the minimum working length of the extension section $L_{w l}$ needed to secure the required carrying line capacity $L_{l}$ is achieved with 3 spools, each having the working length $l_{w l \_s p}=0.30 \mathrm{~m}$. Moreover, the design with three spools is the most preferable option in terms of reliability of operation as it demonstrates the least degree of the major disadvantage inherent in all extension-type systems, i.e. complexity of spool matching in the course of their progressive advance towards each other. 
A design concept of the delivery vehicle for water and bottom sediment sampling (Fig. 3) was developed with due account for the obtained geometrical dimensions of the spools and their number.

A motor (2) is located in the delivery vehicle housing (1) inside a sealed box (3) filled with neutral organosilicon fluid and fitted with a diaphragm (4) to balance the pressure. The motor (2) is connected to a gear box with a power-takeoff shaft (5) that drives the extension-type pulling-and-running gear (6) which carrying line (7) carries a load (8). The gear box with a PTO shaft is needed to simultaneously drive the spooling assembly and the drive spindle of the extension-type pulling-and-running gear.

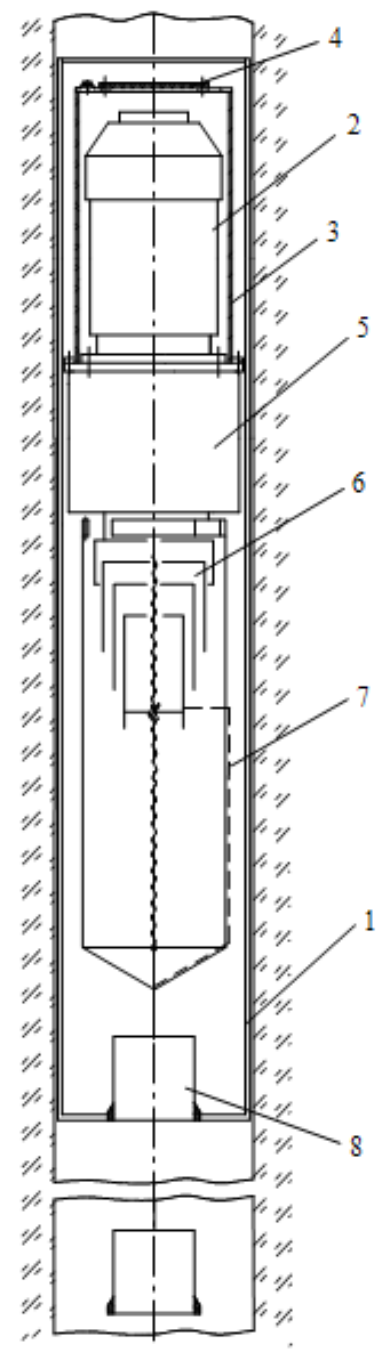

Fig. 3. Design concept of delivery vehicle

The gear box needs to fit in the envelope dimensions of the delivery vehicle and secure uniformity of carrying line winding onto the spools as well as the required travel speed of the research module. Its design should coordinate the rotation rates of the spooling assembly $n_{s a}$ and the drive spindle $n_{d s}$, which values depend on the following parameters:

- Torque-frequency characteristics of the selected motor;

- Thread geometry of the drive spindle;

- Carrying line diameter.

Fig. 4 shows a possible original design of the gear box that ensures twice as fast rotation of the spooling assembly $n_{s a}$ as that of the drive spindle $n_{d s}$.

The gear box (1) is cylindrical in shape and has a threaded connection to the housing cover (2). The gear box (1) houses a four-pass gear assembly, which passes are created by interengagement of pinion shafts $3,4,5,6$ and wheels 7,8,9,10 respectively. The driving pinion shaft (1) is coupled to the electric motor with a spline joint, while the driven shaft (11) is connected to the drive spindle of the extension-type gear with a coupling that is an integral part of the spindle. 
Power take-off is arranged at the second pass of the gear assembly with a wheel (12) that is mounted on a pinion shaft (13) and comes into gear with wheel (8). The other end of the pinion shaft (13) is engaged with the internal gear rim of the spooling assembly (not shown in the drawing). The bearing assemblies of the gear box (14) are set on four successively mounted disks (15) that are axially fixed by spacing sleeves (16).

The following number of teeth were defined for the wheels and the pinion shafts during the design stage:

- The number of teeth for pinion shafts 3, 4, 5, 6: $z_{3}=z_{4}=z_{5}=z_{6}=12$;

- The number of teeth for wheels 7, 8, 9, 10: $z_{7}=z_{8}=z_{9}=z_{10}=36$;

- The number of teeth for wheel 12: $z_{12}=24$;

- The number of teeth for pinion shaft 13: $z_{13}=10$;

- The number of teeth for the internal gear rim of the spooling assembly: $z_{s a}=70$.

Then the overall gear ratio of the four-pass drive of the drive spindle $u_{d s}$ equals:

$$
u_{d s}=\frac{z_{7}}{z_{3}} \cdot \frac{z_{8}}{z_{4}} \cdot \frac{z_{9}}{z_{5}} \cdot \frac{z_{10}}{z_{6}}=\frac{36}{12} \cdot \frac{36}{12} \cdot \frac{36}{12} \cdot \frac{36}{12}=81,
$$

While the gear ratio of the spooling assembly drive $u_{s a}$ equals:

$$
u_{s a}=\frac{z_{7}}{z_{3}} \cdot \frac{z_{8}}{z_{4}} \cdot \frac{z_{12}}{z_{8}} \cdot \frac{z_{s a}}{z_{13}}=\frac{36}{12} \cdot \frac{36}{12} \cdot \frac{24}{36} \cdot \frac{70}{10}=42 .
$$

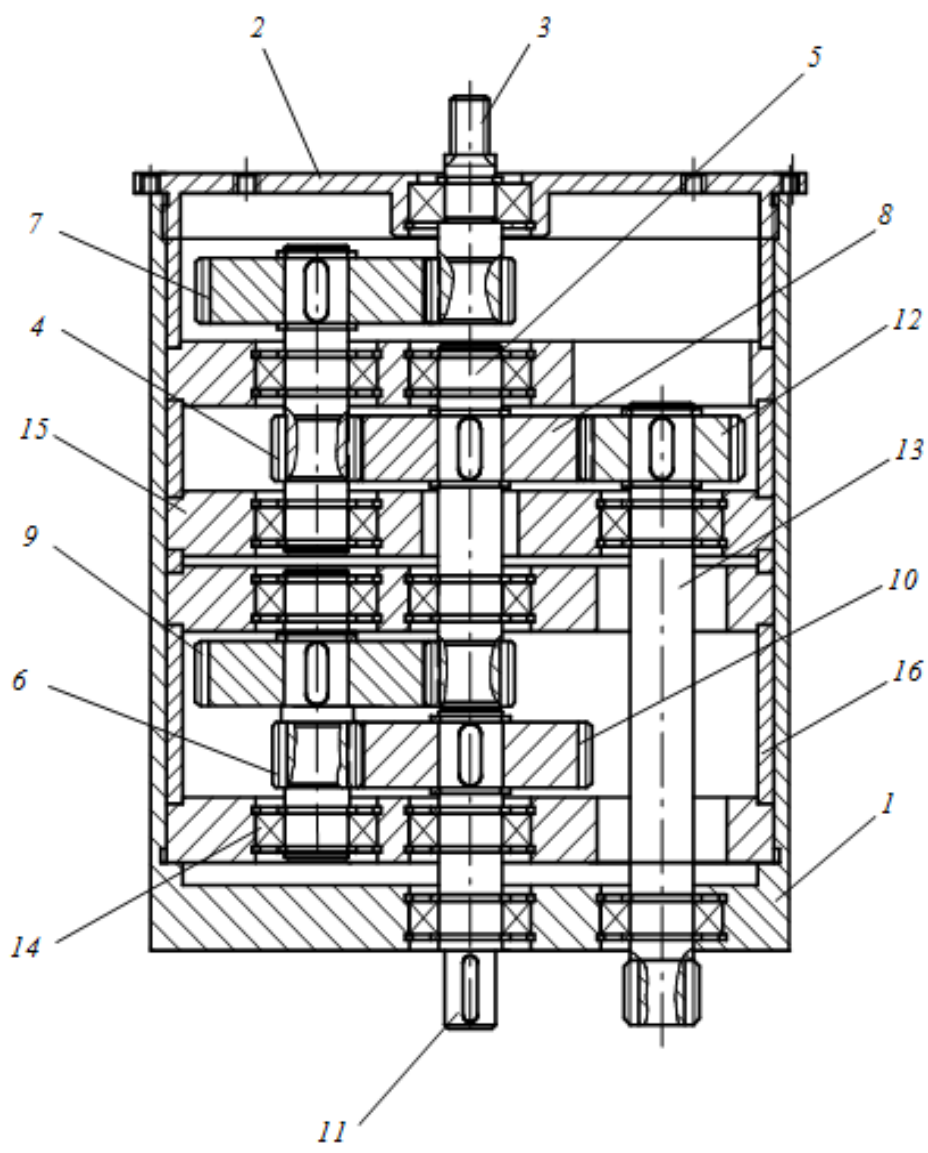

Fig. 4. Design of gear assembly with power-takeoff shaft

The correlation of gear ratios of the drive spindle $u_{d s}$ and the spooling assembly $u_{s a}$ :

$$
\begin{gathered}
u_{s a / d s}=\frac{u_{s a}}{u_{d s}}=\frac{81}{42}=1,93 \\
\Delta u_{s a / d s}=\frac{2-1,93}{2} 100 \%=3,5 \% \leq 4 \%
\end{gathered}
$$


$\Delta u_{m / s} \leq 4 \%$, which is acceptable in designing multiple gearings. In case it is required to obtain another value of the gear ratios of the drive spindle $u_{d s}$ and the spooling assembly $u_{s a}$, it is possible to introduce necessary changes in the gear box design, i.e. increase or decrease the number of gearing passes or arrange a powertakeoff at a different rather than 2 nd gear pass.

\section{III.RESULTS}

The performed research resulted in creation of a fundamentally new design of the pulling-and-running gear for the delivery vehicle. This design is protected with RF Patent No. 2602241, E21B 23/03, published on October 20, 2016.

The technical outcome of this invention is the creation of a extension-type pulling-and-running gear that would secure running to a significant depth and pulling of a load, e.g. research instruments and equipment, drilling tools, which dimensions allow passing through small-size deep boreholes, for example drilled in Antarctic ice shield.

An original design of a gear box was also developed to fit in with the envelope dimensions of the delivery vehicle and secure uniformity of carrying line winding onto the spools as well as the required travel speed of the research module.

\section{IV.DISCUSSIONS}

As it was stated earlier, the performed analysis of commercially available pulling-and-running gears proved that none of them meets the specified requirements. Thus, a patent search was performed that helped to identify a number of developments described below, which to a certain extent meet the specified requirements, but are characterized with critical weaknesses.

Extension-type drill feed (RF Patent No. 2018656, E21C 11/00, published on August 30, 1994) that consists of two coaxial cylinders and a tubular rod, which has a tube with an additional duct fixed in-between the head and the piston. The rod wall close to the piston has radial ports, while the piston section has lengthwise passage. The disadvantages of this design include significant dimensions and the need for compress air for its operation.

Arrangement to control technical condition of cased boreholes (RF Patent No. 2380535, E21B 47/00, published on January 27,2010 ) that consists of a housing, a driven rotor, a noncontact sensor, a cylinder guide designed as a sealed telescopic arrangement of two sleeves, a screw-gear actuator acting on the sleeve bottoms, and surface equipment. The main limitation of this design concept is the need to place an additional driver inside the rotor, which increases the axial diameter of the unit and does not allow it to be used in small-size deep boreholes.

Extension gear for telescope boom (RF Patent No. 2083471, B66C 23/04, published on July 10, 1997) that contains a motor kinematically connected to a drive spindle, a nut interacting to the drive spindle, and a highfrequency generator. The disadvantages of this design concept are its significant dimensions and high metal intensity, which do not allow it to be used for pulling and running operations in small-size boreholes.

A telescope assembly (RF Patent No. 2180314, B66C 23/687, published on March 10,2002) that contains a fixed bearing and moving sections, an assembly to move the sections designed as two hydraulic cylinders connected in series, and an operating device mounted at the end of the unit. At the same time, the body of one of the hydraulic cylinder is pivotally connected to the middle section. The main disadvantage of this design is the need for a hydraulic drive which makes the unit significantly more complicated, increases its dimensions and does not allow to operate it in small-size boreholes.

Adjustable telescope assembly (RF Patent No. 2328629, B66C 23/ 687, F16C 3/02, published on July 10, 2008) that contains an internal and external concentric cartridges and longitudinal screw pairs, each of which is made up of a nut and a screw. The cartridges are interconnected with circular rows of rolling contact bearings; the nut of each screw pair is made integral with the internal cartridge, while the screw of the pair is connected to the drive through a jointing sleeve and an angular-contract bearing. The main disadvantage of this unit is that it does not allow long distance travels.

A method to extend and retract a telescope cylinder and an arrangement to achieve this (RF Patent No. 2083884, F15B 15/16, published on July 10, 1997), which was used as a prototype, and that contains a housing, a driving unit, a driving screw, telescope cylinders, retention and locking elements. The main disadvantage of this design is the need for a process pressure (energy carrier) to lock the cylinder sections, which makes both the unit design and the control process more complicated, and does not allow to travel long distances in restricted space of small-size deep boreholes.

The indicated disadvantages of the developments concerned demonstrate that they cannot be used in designing a pulling-and-running gear for the delivery vehicle to be used for sampling water and bottom sediments in Lake Vostok. This explains the need to create a fundamentally new design of the pulling-and- 
running gear for the delivery vehicle. This design is protected with RF Patent No. 2602241, E21B 23/03, published on October 20, 2016.

\section{CONCLUSIONS}

Lake Vostok in Antarctica is a unique natural system which further investigation assumes collection of the lake water and bottom sediment samples with strict adherence to environmental safety principles of work execution.

The performed analysis of commercially available pulling-and-running gears and research developments proved that none of them meets the specified requirements, above all in terms of their dimensions. Specific features of further surveys of Subglacial Lake Vostok and the delivery vehicle design based on proven parts of the drilling assembly require development of a fundamentally new design of the pulling-and-running gear. This task was successfully completed, which was confirmed by RF Patent No. 2602241, E21B 23/03, published on. October 20, 2016. The proposed design of the pulling-and-running gear will secure delivery of the research tools and equipment into the lake to the depths ranging from 0 to $700 \mathrm{~m}$.

As the next step, basing on the performed developments, it is planned to create a prototype model of the extension-type pulling-and-running gear and the delivery vehicle with their subsequent testing. It is planned to test the prototype model during the seasonal shift period of the 63rd Russian Antarctic Expedition (December 2017 - January 2018) first using a test-bench and finally directly in Borehole 5G-3.

\section{VI.RECOMMENDATIONS}

The information presented in this paper can be of interest for scientists and researchers who study subglacial lakes in Antarctica as well as for designers of drilling equipment and pulling-and-running gears.

\section{ACKNOWLEDGEMENTS}

The authors would like to express their deep gratitude to Galina V. Sokolova for her assistance in preparing this paper.

\section{REFERENCES}

[1] Antarktika. Geomorfologicheskiy Atlas (Antarctic. Geomorphological Atlas). St. Petersburg: "Karta" Publishing House, 2011. 255 p. [In Russian.]

[2] Masolov V.N., Popov S.V., Lukin V.V., Popkov A.M. Rel`ef dna i vodnoe telo podlednikovogo ozera Vostok, Vostochnaia Antarktida (Bottom Topography and Water Body of Vostok Subglacial Lake, East Antarctic) // DAN. 2010. P. 433. № 5. p. 693-698. [In Russian.]

[3] Leitchenkov G., Antonov A., Luneov P., Lipenkov V. 2016. Geology and environments of subglacial Lake Vostok. Phil. Trans. R. Soc. A. 2015. Vol. 373, 20140303. (doi: 10.1098/rsta. 2014.0303).

[4] Lukin V.V. Put' k izucheniju vod ozera Vostok otkryt (Door to Study Waters of Vostok Lake is open) // Issues of Arctic and Antarctic. 2012. № 1(91). p. 5-19. [In Russian.]

[5] Kudryashov, B.B., N.I. Vasiliev, R.N. Vostretsov, A.N. Dmitriev, V.M. Zubkov, A.V. Krasilev, P.G. Talalay, N.I. Barkov, V.Ya. Lipenkov, J.R. Petit. 2002. Deep ice coring at Vostok Station (East Antarctica) by an electromechanical drill. Mem. Natl Inst. Polar Res. Spec. Issue 56. (Proc. of the Fifth Int. Workshop on Ice Drilling Technology, Nagaoka, 30 October - 1 November 2000). 91-102.

[6] Vasiliev, N.I., P.G. Talalay, N.E. Bobin, V.K. Chistyakov, V.M. Zubkov, A.V. Krasilev, A.N. Dmitriev, S.V. Yankilevich, and V.Ya. Lipenkov. 2007. Deep drilling at Vostok Station, Antarctica: history and last events. Annal. Glaciol., 47. 10-23.

[7] Augustin L., F. Motoyama, H. Wilhelms, S. Johnsen, S.B.Hansen, P. Talalay, N. Vasiliev. 2007. Drilling comparison in 'warm ice' and drill design comparison. Ann. Glaciol., 47, 73-78.

[8] Nikolai I. Vasilev, Alexey V. Bolshunov and Sergei A. Ignatiev. Inertial Mechanical Reamer for Borehole 5G-3 Conditioning for Penetration into Subglacial Lake Vostok. International Journal of Applied Engineering Research., Volume 12, Number 5 (2017) pp. 561-566.

[9] Kudryashov, B.B., V.K. Chistyakov and V.S. Litvinenko. 1991. Burenie skvazhin v usloviyah izmeneniya agregatnogo sostoyaniya gornih porod (Bore-hole drilling in the condition of rock aggregate changes). Leningrad, Nedra, 1-295. [In Russian.]

[10] Kudryashov, B.B., V.K. Chistyakov, V.A. Morev. 1983. Bureniye ledianogo pokrova Antarktidi teplovim sposobom. 25 let Sovetskoy Antarkticheskoy ekspeditsii. [Thermal drillingin Antarctic ice sheet. 25th Anniversary of the Soviet Antarctic Expedition.] L. Gidrometeoizdat. 149-158. [In Russian.]

[11] Lukin, V.V. and N.I. Vasiliev, Technological aspects of the final phase of drilling borehole 5G and unsealing Vostok Subglacial Lake, East Antarctica. Annal. Glaciol., 55(65). 83-89.

[12] Pashkevich, V.M. and V.K. Chistyakov, 1989. Obespechenie ustoychivosti stvola skvazhini pri glubokom burenii v lednikovih pokrovah (Ensuring of bore-hole shaft stability when deep drilling in the ice covers). Antarktika (The Antarctic), 28. 39-50. [In Russian.]

[13] N. I. Vasilev, A.V. Bolshunov, A.N. Dmitriev and A.V. Podoliak. Round-Trip Assembly for Investigations of Subglacial Lake Vostok. International Journal of Applied Engineering Research., Volume 11, Number 9 (2016), pp 6376-6380. 